Canadian

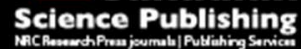

Canadian Journal of Microbiology Revue canadienne de de microbiologie

\title{
Enhancement of fengycin production in Bacillus amyloliquefaciens by genome shuffling and relative gene expression analysis using RT-PCR
}

\begin{tabular}{|r|l|}
\hline Journal: & Canadian Journal of Microbiology \\
\hline Manuscript ID & cjm-2015-0734.R2 \\
\hline Danuscript Type: & Article \\
\hline Complete List of Authors: & $\begin{array}{l}\text { Zhao, Junfeng; College of Food Science and Engineering, Henan University } \\
\text { of Science and Technology } \\
\text { Zhang, Chong; Colleges of Food Science and Technology, Nanjing } \\
\text { Agricultural University } \\
\text { Lu, Jing; Nanjing Agricultural University } \\
\text { Lu, Zhaoxin; Colleges of Food Science and Technology, Nanjing Agricultural } \\
\text { University }\end{array}$ \\
\hline Keyword: & $\begin{array}{l}\text { Genome shuffling, Bacillus amyloliquefaciens, Fengycin, CT (threshold } \\
\text { cycle), RT-PCR }\end{array}$ \\
\hline &
\end{tabular}




\section{Introduction}

\section{fmb@njau.edu.cn} engineering.

shuffling and relative gene expression analysis using RT-PCR

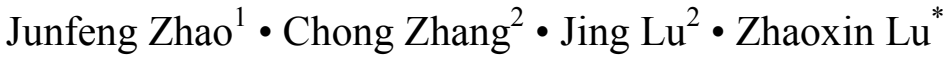

${ }^{1}$ College of Food Science and Engineering, Henan University of Science and Technology, Tianjing Road, Luoyang 471003, People's Republic of China.

${ }^{2 *}$ College of Food Science and Technology, Nanjing Agricultural University, Nanjing 210095, Jiangsu, People's Republic of China.

\section{*Corresponding author: Tel: +86-25-4396583 Fax: +86-25-4396431 E-mail:}

Abstract:Genome shuffling is an efficient approach for the rapid engineering of microbial strains with desirable industrial phenotypes. In this study, we used genome shuffling in an attempt to improve fengycin production of the wild-type strain Bacillus amyloliquefaciens ES-2-4 . After two rounds of genome shuffling, a high-yield recombinant F2-72 (FMB72) strain that exhibited 8.30- fold increases in fengycin production was obtained. Comparative analysis of synthetase gene ( fen $\mathrm{A})$ expression was conducted between the initial and shuffled strains using FQ (fluorescent quantitation) RT-PCR. Delta CT (threshold cycle) relative quantitation analysis revealed that fengycin synthetase gene ( fenA ) expression at the transcriptional level in the FMB72 strain was 12.77 -fold greater than in the ES-2-4 wild type. The shuffled strain has a potential application in food and pharmaceutical industries. At the same time, the analysis of improved phenotypes will provide more valuable data for inverse metabolic

Key words: Genome shuffling , Bacillus amyloliquefaciens, Fengycin, CT (threshold cycle), RT-PCR 
$1 \quad$ Bacillus strains can produce many types of bioactive peptides that are synthesized

2 non-ribosomally by a large multifunctional enzyme complex. Of these, the lipopeptide

3 fengycin has specifical anti filamentous fungal activity (Vanittanakom et al. 1986).

4 Fengycin is biosynthesized by five NRPSs, Fen1-Fen5, respectively is coded by the gene

5 fen $A-E$ (Steller et al. 1999). Fengycin consists of a $\beta$-hydroxy fatty acid connected to the

$6 \quad$ N-terminus of a decapeptide including four D-amino acid residues and the rare amino

7 acid L-ornithine. The C-terminal residue of the peptide moiety is linked to the tyrosine

8 residue at position 3 , forming the branching point of the acylpeptide and the

9 eight-membered cyclic lactone (Stein et al. 2005; Wang et al. 2010). Fengycin has

10 potential applications in plant disease biocontrol (Ongena et al. 2008), biomedicine, food

11 (Bie et al. 2005) and cosmetics (Kanlayavattanakul et al. 2010) industries. Therefore, it

12 is particularly significant to improve fengycin production in industrial Bacillus strains.

13 Genome shuffling is an efficient approach for the rapid improvement of microbial

14 phenotypes (Zhang et al. 2002). Genome shuffling involves generation of mutant strains

15 that have an improved phenotype, followed by multiple rounds of protoplast fusion to

16 allow recombination between genomes (Zhang et al. 2013; Zhang et al. 2014; Lv et al.

17 2013). A strain with a high yield of a desired product can rapidly be obtained by genome

18 shuffling without knowledge of the metabolic regulatory mechanism. Two rounds of

19 genome shuffling were shown to be sufficient to achieve results that had previously

20 required 20 rounds of mutagenesis and screening (Zhang et al. 2002). In the present study,

21 genome shuffling was used to increase the yield of fengycin from B.amyloliquefaciens.

22 The mechanisms that gave rise to the improved traits were explored by detecting the fen $A$ 23 target mRNA. 


\section{$1 \quad$ Materials and methods}

\section{Strains and culture conditions}

3 B. amyloliquefaciens ES-2 is an endophyte isolated from the Chinese medicinal plant

4 Scutellaria baicalensis Georgi (Sun et al. 2006). B. amyloliquefaciens ES-2-4 was got by

$520 \mathrm{keV} \mathrm{N}^{+}$ion beam implantation (Fang et al. 2006). The yield of the peptides increased

6 by $15.2 \%$ compared to ES-2. These strains are conserved by the Key Laboratory of Food

7 Processing and Quality Control of the Food Science and Technology College at Nanjing

8 Agricultural University, Nanjing, China. B. amyloliquefaciens ES-2-4 was cultured in

9 potato dextrose agar (PDA) media at $37^{\circ} \mathrm{C}$. All microorganisms were maintained in $\mathrm{BPY}$

10 supplemented with $20 \%(\mathrm{v} / \mathrm{v})$ glycerol and stored at $-70^{\circ} \mathrm{C}$. Seed medium (BPY) (peptone

$1110.0 \mathrm{~g} / \mathrm{L}$, beef extract $5.0 \mathrm{~g} / \mathrm{L}$, yeast extract paste $5.0 \mathrm{~g} / \mathrm{L}$, glucose $10.0 \mathrm{~g} / \mathrm{L}, \mathrm{NaCl} 5.0$

$12 \mathrm{~g} / \mathrm{L}$ ) and fermentation medium (modified Landy) (L-sodium glutamate $4.0 \mathrm{~g} / \mathrm{L}$, glucose

$1342.0 \mathrm{~g} / \mathrm{L}, \mathrm{CuSO}_{4} 0.16 \mathrm{mg} / \mathrm{L}, \mathrm{MgSO}_{4} 0.5 \mathrm{~g} / \mathrm{L}, \mathrm{KCl} 0.5 \mathrm{~g} / \mathrm{L}, \mathrm{KH}_{2} \mathrm{PO}_{4} 1.0 \mathrm{~g} / \mathrm{L}, \mathrm{FeSO}_{4} 0.15$

$14 \mathrm{mg} / \mathrm{L}, \mathrm{MnSO}_{4} 5.0 \mathrm{mg} / \mathrm{L}$ ) were adjusted to $\mathrm{pH}$ 7.0. SMM, adjusted to $\mathrm{pH}$ 6.5, contained

$15 \mathrm{MgCl}_{2} \cdot 6 \mathrm{H}_{2} \mathrm{O} 4.07 \mathrm{~g} / \mathrm{L}$, sucrose $171.14 \mathrm{~g} / \mathrm{L}$, and maleicacid $2.32 \mathrm{~g} / \mathrm{L}$ as a stabilizer.

16 Lysozyme was dissolved in SMM, sterilized by filtration through a $0.22 \mu \mathrm{m}$ membrane

17 filter and stored at $-20^{\circ} \mathrm{C}$. PEG 6000 (40\%) was prepared with SMM.

18 Mutagenesis

19 The induction of mutation was carried out by treatment of $B$. amyloliquefaciens ES-2-4

20 cells with $0.3 \mathrm{mg} / \mathrm{mL}$ nitrosoguanidine (NTG) for $30 \mathrm{~min}$ or antibiotics $(0.5 \mathrm{U} / \mathrm{mL}$

21 penicillin, $0.15 \mathrm{U} / \mathrm{mL}$ streptomycin or $3 \mathrm{U} / \mathrm{mL}$ amikacin sulfate) for $15 \mathrm{~min}$ and then

22 spread on the resistance media plate. The plates were incubated at $30^{\circ} \mathrm{C}$ for 2 days. The 
1 colonies were selected to carry out shake flask analysis. The strains with higher fengycin

2 concentration were obtained and taken as the starters for genome shuffling.

\section{Preparation of protoplast}

4 The cells of each mutant strain were statically cultured at $37^{\circ} \mathrm{C}$ for $5 \mathrm{~h}$ in $50 \mathrm{~mL} \mathrm{BPY}$

5 seed medium. Cells were harvested by centrifugation, washed, and resuspended in SMM.

6 Protoplasts were prepared by addition of lysozyme to final concentration of $0.2 \mathrm{mg} / \mathrm{mL}$

$7 \quad\left(37^{\circ} \mathrm{C}\right.$ for $\left.15 \mathrm{~min}\right)$ and collected by centrifugation at $2500 \mathrm{rpm}$ for $10 \mathrm{~min}$ and then

8 suspended in SMM ( Zhao et al. 2012) .

$9 \quad$ Genome shuffling

10 Equal number of protoplasts from different populations was mixed and divided equally

11 into two parts. One part was treated with UV for $60 \mathrm{~min}$, and the other was headed at

$12100^{\circ} \mathrm{C}$ for $30 \mathrm{~min}$. Both inactivated protoplasts $\left(10^{6} / \mathrm{mL}\right)$ were mixed in a cell ratio of $1: 1$,

13 centrifugated and resuspended in $0.2 \mathrm{~mL}$ of SMM. Nine volumes of $40 \%$ PEG 6000 in

14 SMM were added to the resuspended protoplast mixture and incubated for $12 \mathrm{~min}$ at

$1537^{\circ} \mathrm{C}$. The fused protoplast was centrifugated, washed, resuspended in $2 \mathrm{~mL} \mathrm{SMM}$, and

$160.1 \mathrm{~mL}$ of sample were regenerated on $\mathrm{RM}$ at $37^{\circ} \mathrm{C}$ for $36 \mathrm{~h}$. The colonies were selected

17 to carry out shake flask analysis and the strains with higher fengycin concentration were

18 obtained and named F1. Subsequent rounds of genome shuffling were carried out by

19 repeating the protoplast fusion described above (Zhao et al. 2012).

\section{Shake flask and bioreactor cultivation}

21 Colonies from PDA (including $0.6 \mathrm{~mol} / \mathrm{L} \mathrm{NaCl}$ ) plates were used to inoculate 
1 overnight cultures in $100 \mathrm{~mL}$ BPY medium. The $180 \mathrm{~mL}$ fermentation medium in shake

2 flasks (1 L) was inoculated with $8 \mathrm{~mL}$ of the overnight cultures at $33^{\circ} \mathrm{C}, 180 \mathrm{rpm}$. Each

3 strain was cultured in three shake flasks.

4 Precultures for bioreactor cultivations were grown in BPY medium at $37^{\circ} \mathrm{C}$ for $24 \mathrm{~h}$.

5 Two preinoculation steps were required before bioreactor cultivations. Bioreactor

6 cultivation were performed in a 20 -L bioreactor using $12 \mathrm{~L}$ of fermentation medium and

7 cultured at $33^{\circ} \mathrm{C}$. During the batch fermentation course, $\mathrm{pH}$ was controlled at 7.0 with

8 automatic addition of $3.0 \mathrm{~mol} / \mathrm{L} \mathrm{NaOH}$ and an agitation speed of $250 \mathrm{rpm}$ was maintained.

9 Silicone oil was served as anti-foam additive.

10 Extraction and detection of fengycin

11 Overnight cultures of Bacillus amyrloliquefaciens were inoculated (5\%, v/v) into $12200 \mathrm{~mL}$ modified Landy medium, and then shaken at $33^{\circ} \mathrm{C}$ and $180 \mathrm{rpm}$ for $36 \mathrm{~h}$. At the 13 end of cultivation, $200 \mathrm{~mL}$ supernatant was treated with $6 \mathrm{~mol} / \mathrm{L} \mathrm{HCl}$ to adjust the $\mathrm{pH}$ to 142.0 and then the antibacterial peptides was extracted with $5 \mathrm{~mL}$ methanol for different 15 times and adjusted the $\mathrm{pH}$ to 7.0. The supernatants were analyzed by reversed-phase 16 HPLC (C18 column, ODS $4.6 \times 250 \mathrm{~mm}$, AGILENT 1100 series). Total lipopeptides 17 were determined by high-performance liquid chromatography (HPLC) (AGILENT 1100 18 series) using a C18 column (ODS $4.6 \times 250 \mathrm{~mm}$ ) with UV detectors. The eluent used was

19 Methyl Cyanides with $1 \%$ trifluoroacetic acid at a flow rate of $0.6 \mathrm{~mL} / \mathrm{min}$. The injection 20 volume of the sample was $20 \mu \mathrm{L}$. For fengycin production, Rhizopus stolonifer was used 21 as an indicator.

\section{Analysis for fengycin, glucose and dry cell weight}


1 Fengycin was determined by high-performance liquid chromatography (HPLC).

2 Glucose was estimated with DNS by measuring the OD (optical density) at $600 \mathrm{~nm}$ with

3 Unic 721 spectrophotometer (Shanghai). Dry cell weight was determined after

4 centrifuging $10 \mathrm{~mL}$ fermentation broth, washed twice with distilled water, and dried to

5 constant weight at $85^{\circ} \mathrm{C}$. The same sample was repeated three times.

\section{$6 \quad$ RT-PCR analysis}

7 Total RNA was extracted from B. amyloliquefaciens cultures using TRIzol Reagent

8 (Invitrogen, Carlsbad, CA, USA) according to the manufacturer's instructions, and then

9 treated with RNase-free DNase. First-strand cDNA was synthesized from total RNA

10 using an RT-PCR kit (Fermentas, Vilnius, Lithuania). Real-time PCR was performed

11 using a real-time PCR SYBR Green Master Mix kit (Toyobo Biologics, Osaka, Japan) on

12 a Rotor-Gene 3000 RT-PCR System (Corbett Research, Australia). Each 25- $\mu$ L PCR

13 reaction contained $10 \mu \mathrm{L}$ of real-time PCR mix, $1 \mu \mathrm{L}$ of template DNA (100 ng), and $2 \mu \mathrm{L}$

14 of $10 \mu \mathrm{mol} / \mathrm{L}$ primers. The PCR conditions were as follows: $95^{\circ} \mathrm{C}$ for $5 \mathrm{~min}$, followed by

1540 cycles of $95^{\circ} \mathrm{C}$ for $15 \mathrm{~s}, 60^{\circ} \mathrm{C}$ for $30 \mathrm{~s}$, and $72^{\circ} \mathrm{C}$ for $30 \mathrm{~s}$. Each reaction was

16 performed in triplicate. Following threshold-dependent cycling, melting was performed

17 from $45-95^{\circ} \mathrm{C}$ at a $0.1^{\circ} \mathrm{C} / \mathrm{s}$ melt rate with a smooth curve setting averaging one point.

18 Primer specificity was verified by melt curve analysis. Band intensities were normalized

19 to the $16 \mathrm{~S}$ rDNA transcript band for $2^{-\Delta \Delta \mathrm{CT}}$ relative quantification (Livak et al. 2001).

$2016 \mathrm{~S}$ rDNA was selected as the housekeeping gene, the fenA gene is the gene of interest.

21 The B. amyloliquefaciens nucleotide sequences for these two genes were obtained from

22 the GenBank database at the National Center for Biotechnology Information (NCBI,

23 http://www.ncbi.nlm.nih.gov/). Primer pairs were designed from these sequences (80-200 
1 bp product length, optimal Tm at $60^{\circ} \mathrm{C}, \mathrm{GC} \%$ between 40 and $60 \%$ ) with the Primer

2 Premier 5.0 software (Applied Biosystems), the 16S rDNA primers used were $\mathrm{F}$

3 (5-CCTACGGGAGGCAGCAG-3) and R (5-ATTACCGC GGCTGCTGG-3) and the

4 fenA primers were F (5- CCATCGGCACTTATTACGGAAAC -3 ) and

5 R(5-TGCGGACAAAGG ACAGGAACT -3).

\section{$6 \quad$ Results and discussion}

\section{$7 \quad$ Strain mutagenesis and mutant screening}

8 Genome shuffling accelerates directed evolution by facilitating recombination within a

9 diverse mutant population. An improved starting point for breeding was required.

10 Genome shuffling amplifies genetic diversity by homologous recombination using

11 protoplast fusion within the selected mutant population (Hida et al. 2007).

12 Consequently, in order to increase the genetic diversity of mutant population, NTG was

13 used to generate the first population of heavy producing mutants of ES-2-4. The cells of

14 the initial strain were sensitive to $0.3 \mathrm{mg} / \mathrm{mL}$ NTG treatment for the clear inhibition zone

15 and then the cells were scraped from different places on the lawn around the inhibition

16 zone. About 115 colonies that showed the biggest transparent haloes were further tested

17 for fengycin production in shake flasks. Antibiotics $(0.5 \mathrm{U} / \mathrm{mL}$ penicillin, $0.15 \mathrm{U} / \mathrm{mL}$

18 streptomycin, $3 \mathrm{U} / \mathrm{mL}$ amikacin sulfate) were used as the mutagenizing agent for the

19 second population of mutants of ES-2-4. The cells spread on plates were exposed in

20 antibiotics solutions during which a killing rate of approximately $90 \%$ was observed. The

21 cells that characteristically produced the biggest zones of fengycin production were

22 chosen; 111 colonies conformed to this standard. Two mutant populations were assumed

23 to possess the capability for the high production of fengycin. During the secondary 
1 screening in shake flask evaluations, 3 NTG mutants, 3 antibiotics mutants were selected

2 from the NTG and antibiotics populations. These six mutants showed small increases,

3 from $7.5 \%$ to $62.0 \%$ (Fig. 1 ) in the production of fengycin . In addition, their high

4 producing capacity was stable and was maintained after at least 20 transfers in

5 shake-flasks. Consequently, these six mutants were used as the starting population for

6 genome shuffling.

\section{$7 \quad$ Genome shuffling}

8 Genome shuffling is dependent on the recursive fusion of protoplasts to allow

9 recombination. This recursive strategy permits the phenotype of interest to be obtained

10 quickly. The high frequency of protoplast formation and regeneration is the basis of the

11 efficiency of genome shuffling. A suitable concentration of lysozyme was necessary to

12 improve the frequency of protoplast formation as judged by osmotic fragility. The

13 frequency of protoplast regeneration was low and so, in a successful attempt to improve

14 this, we replaced sucrose in the RM with $0.6 \mathrm{~mol} / \mathrm{L}$ sodium chloride. The protoplasts of

15 the NTG, and antibiotics mutants were subjected to a first round of pool-wise recursive

16 protoplast fusion. The resulting populations were screened for individuals with improved

17 fengycin production using the selective plates. After the first fusion, 147 colonies were

18 assayed for fengycin production in shake flask. We found two isolates showing higher

19 concentration of fengycin, named as B. amyloliquefaciens F1-140 (65.0 mg/L ) and B.

20 amyloliquefaciens F1-142 (65.2 mg/L ), respectively (Fig. 1). These two strains were then

21 used in an additional round of shuffling. The resulting second round population of 134

22 isolates was assayed for fengycin production in shake flask. Three colonies (F2) were 
1 found to show higher concentration of fengycin. The mutant showing the highest

2 fengycin production level was selected and named as B. amyloliquefaciens F2-72 (Fig. 1).

3 The F2-72 (FMB72) mutants exhibited $81.4 \mathrm{mg} / \mathrm{L} \quad$ (Fig. 1) fengycin yield which is 2.03

4 times improvement compared to the initial strain.

5 Characterization of fengycin production, glucose consumption and cell growth of 6 ES-2-4 and FMB72 in bioreactor

7 The fengycin production, glucose consumption and cell growth of FMB72 were 8 compared with ES-2-4 in the 20 L bioreactor. In an attempt to evaluate the effects of

9 scale-up fermentation on the genome shuffled strain for fengycin production with cell 10 growth, glucose consumption. Consistent with shake flask results, FMB72 obtained 11 fengycin production of $450.51 \mathrm{mg} / \mathrm{L}$, which was 8.30 times increase compared to the 12 ES-2-4 at $42 \mathrm{~g} / \mathrm{L}$ glucose concentration after $36 \mathrm{~h}$. It also exhibited better growth and 13 more rapid glucose consumption under the same condition (Fig. 2). The cell growth 14 characterization was consistent with fengycin production. The dry cell weight of FMB72

15 reached $6.13 \mathrm{~g} / \mathrm{L}$, whereas ES-2-4 was $5.24 \mathrm{~g} / \mathrm{L}$. The specific growth rate of FMB72 was

$16 \quad 16.98 \%$ higher than ES-2-4, when it was determined from the beginning to the end of the 17 batch fermentation. The rate of glucose consumption of genome-shuffled strain was 18 higher than that of ES-2-4. There was $6.64 \mathrm{~g} / \mathrm{L}$ residual glucose left in the medium when 19 cultivated with ES-2-4, while only 4.23g/L glucose left with FMB72 at the end of the 20 fermentation. The results showed the FMB72 produced more antimicrobial lipopeptides 21 compared with ES-2-4. As is shown in Fig.2 that the final fengycin concentration of 22 FMB72 was 8.30 times greater than ES-2-4.

23 Comparative mRNA analysis between the shuffled and initial strains 
1 The initial strain and shuffled strain were assayed using real-time PCR respectively.

2 The data are presented as the fold change in gene expression normalized to an

3 endogenous reference gene and relative to the initial control. The evaluation of $2^{-\Delta \Delta C T}$

4 indicates the fold change in gene expression relative to the initial control. The amount of 5 target, normalized to an endogenous reference and relative to the initial, is calculated 6 according to the following equation;

$$
\mathrm{F}=2^{-\Delta \Delta \mathrm{CT}} \text { (Livak et al. 2001) }
$$

8 Where $\Delta \Delta \mathrm{C}_{\mathrm{T}}=\left(\mathrm{CT}\right.$, fen $\mathrm{A}^{-} \mathrm{CT}, 16 \mathrm{~S}$ rDNA $)$ FMB72 $-(\mathrm{CT}$, fen $\mathrm{A}-\mathrm{CT}, 16 \mathrm{~S}$ rDNA $)$ ES-2-4. The

9 normalized expression was calculated by averaging three CT values for the reference

10 gene (16S rDNA) and for the gene of interest (fenA). As shown in Fig. 4, the expression

11 of $f e n \mathrm{~A}$ in the shuffled strain was 12.77 times its expression in the initial strain.

12 In conclusion, the production of fengycin in B. amyloliquefaciens can be improved by

13 genome shuffling and the expression of fenA in the shuffled strain was higher than its

14 expression in the initial strain. The analysis of improved phenotypes will provide more

15 valuable data for inverse metabolic engineering.

\section{Acknowledgments}

17 This study was supported by the National Natural Science Foundation of China (No.

18 31271936), the National Research Program of China (No. 2011BAD23B05), and the

19 Project Funded by the Priority Academic Program Development of Jiangsu Higher

20 Education Institutions.

\section{$21 \quad$ References}

22 Bie X.M., Lu Z.X., Lu F.X., and Zeng X.X. 2005. Screening the main factors affecting 23 extraction of the antimicrobial substance from Bacillus sp. fmbJ using 
Plackett-Burman method. World J Microbiol Biotechnol. 21: 925-928.

2 Fang C.J., Lu Z.X., Sun L.J., Lu F.X., and Bie X.M. 2006. Study on mutation breeding

3 and fermentation of antimicrobial lipopeptides yielding bacterium with $20 \mathrm{keV} \mathrm{N}^{+}$ion

$4 \quad$ beam implantation. J Radiat Res Radiat Process. 24:333-336.

5 Hida H., Yamada T., and Yamada Y. 2007. Genome shuffling of Streptomyces sp.

6 U121 for improved production of hydroxycitricacid. Appl Microbiol Biotechnol.

$7 \quad 73: 1387-1393$.

8 Kanlayavattanakul M., and Lourith N. 2010. Lipopeptides in cosmetics. Int J Cosmet $9 \quad$ Sci. 32: 1-8.

10 Livak K.J., and Schmittgen T.D. 2001. Analysis of relative gene expression data using 11 real-time quantitative PCR and the $2^{-\Delta \Delta \mathrm{CT}}$ method. Methods. 25:402-408.

12 Lv X.A., Li Y.D., and Jin Y.Y. 2013. Genome shuffling of Streptomyces 13 viridochromogenes for improved production of avilamycin. Applied Microbiology 14 and Biotechnology. 97(2): 641-648.

15 Ongena M., and Jacques P. 2008. Bacillus lipopeptides: versatile weapons for plant 16 disease biocontrol. Trends Microbiol. 16: 115-125.

17 Steller S., Vollenbroich D., Leenders F., Stein T., Conrad B., and Hofemeister J. 18 1999.Structural and functional organization of the fengycin synthetase multienzyme system from Bacillus subtilis b213 and A1/3. Chem Biol. 6: 31-41.

Stein T . 2005. Bacillus subtilis antibiotics: structures, syntheses and specific functions. Molecular Microbiology. 56(4):845-857.

Sun L.J., Lu Z.X., Bie X.M., Lu F.X., and Yang S.Y. 2006. Isolation and characterization of a co-producer of fengycins and surfactins, endophytic Bacillus amyloliquefaciens 
ES-2, from Scutellaria baicalensis Georgi. World J Microbiol Biotechnol. 22:1259-1266.

Vanittanakom N., Loeffler W., Koch U., and Jung G. 1986. Fengycin - a novel antifungal lipopeptide antibiotic produced by Bacillus subtilis $\quad$ F-29-3. J Antibiot (Tokyo) . 39: $888-901$.

Wang Y., Lu Z.X., and Bie X.M. 2010. Separation and extraction of antimicrobial lipopeptides produced by Bacillus amyloliquefaciens ES-2 with macroporous resin. Eur Food Res Technol. 231:189-196.

Zhang J., Wang X., and Diao J. 2013. Streptomycin resistance-aided genome shuffling to improve doramectin productivity of Streptomyces avermitilis NEAU1069. Journal of Industrial Microbiology. 40(8):877-889.

Zhang Y.F., Liu S.Y., and Du Y.H. 2014. Genome shuffling of Lactococcus lactis subspecies lactis YF11 for improving nisin Z production and comparative analysis. Journal of Dairy Science. 97(5):2528-2541.

Zhang Y.X., Perry K., Vinci V.A., Powell K., Stemmer WPC., and del Cardayre'S. 2002. Genome shuffling leads to rapid phenotypic improvement in bacteria. Nature. 415:644-646.

Zhao J.F., Li Y. H., Zhang C.,Yao Z.Y., and Lu Z.X. 2012. Genome shuffling of Bacillus amyloliquefaciens for improving antimicrobial lipopeptide production and an analysis of relative gene expression using FQ RT-PCR. J Ind Microbiol Biotechno. 39:889-896. 
1 Fig. 1 Comparison of the wild-type and mutant strains of Bacillus amyloliquefaciens for

2 fengycin production in BPY medium in shakeflasks. ES-2-4, wild-type of Bacillus

3 amyloliquefaciens; N, NTG mutant stains; K, antibiotics mutant stains, F1, strains from

4 the first round of genome shuffling; F2, strains from the second round of genome

5 shuffling.

6 Fig.2 Comparison of cell growth (triangle), glucose consumption (circle) and fengycin

7 production (square) by Bacillus amyloliquefaciens ES-2-4 (open) and Bacillus

8 amyloliquefaciens FMB72 (closed) in a 20-L bioreactor. Samples of the experiments with

9 initial glucose concentrations of $42 \mathrm{~g} / \mathrm{L}$ were analyzed every $4 \mathrm{~h}$. DCW, dry cell weight.

$10 \quad$ Fig.3 Suppressive effect of the supernatants on Rhizopus stolonifer obtained after growth

11 of (A) Bacillus amyloliquefaciens ES-2-4 and (B) FMB72 in modified Landy medium.

12 ES-2-4, wild-type of Bacillus amyloliquefaciens; FMB72, a strain produced after two

13 rounds of genome shuffling.

14 Fig.4 qRT-PCR analysis of mRNA expression of fenA gene. Asterisks indicate a

15 statistically significant difference $(\mathrm{P}<0.05)$ between the parental strain $\mathrm{ES}-2-4$ and

16 recombination strain FMB72. 
Figure 1

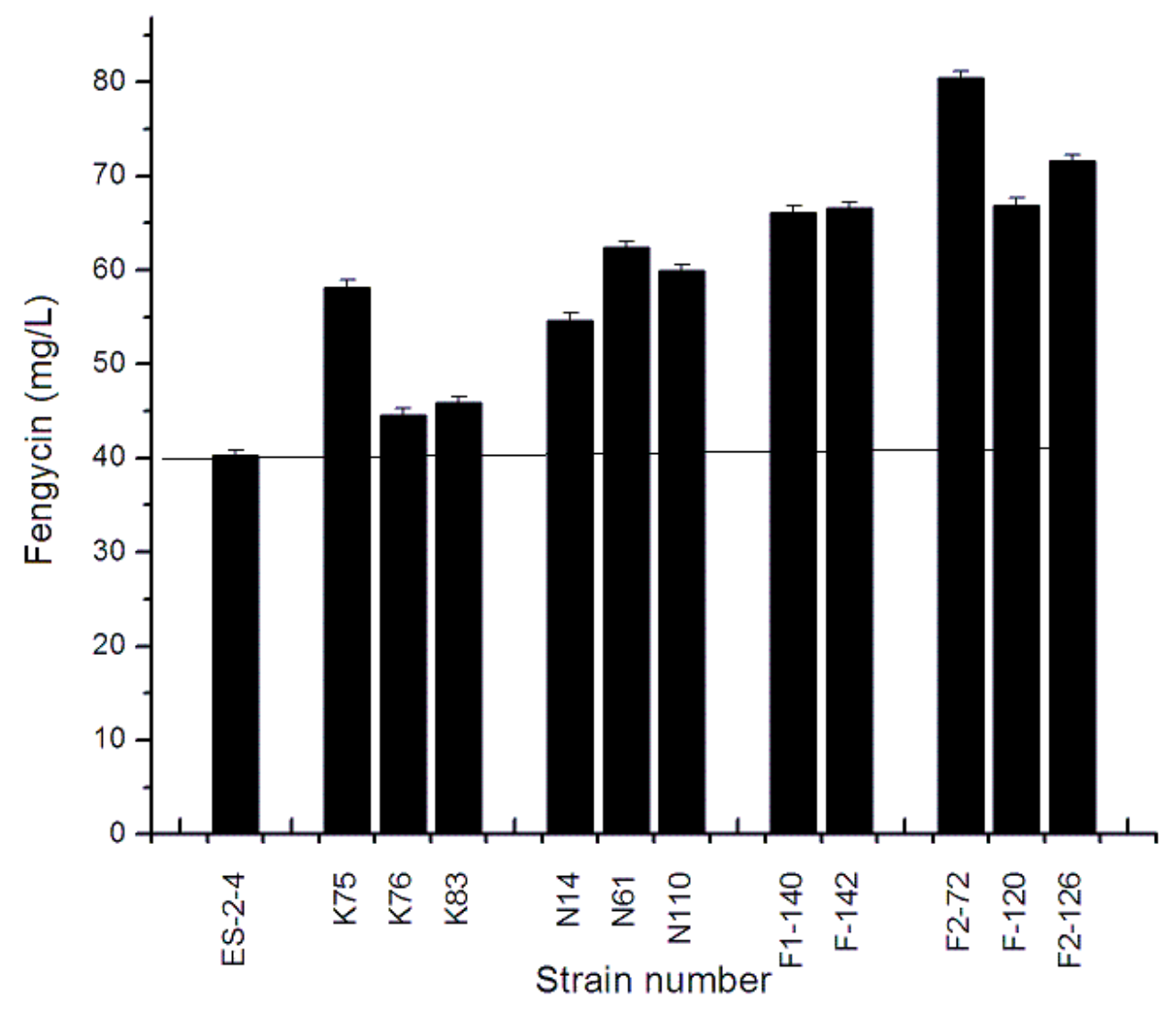


Figure 2

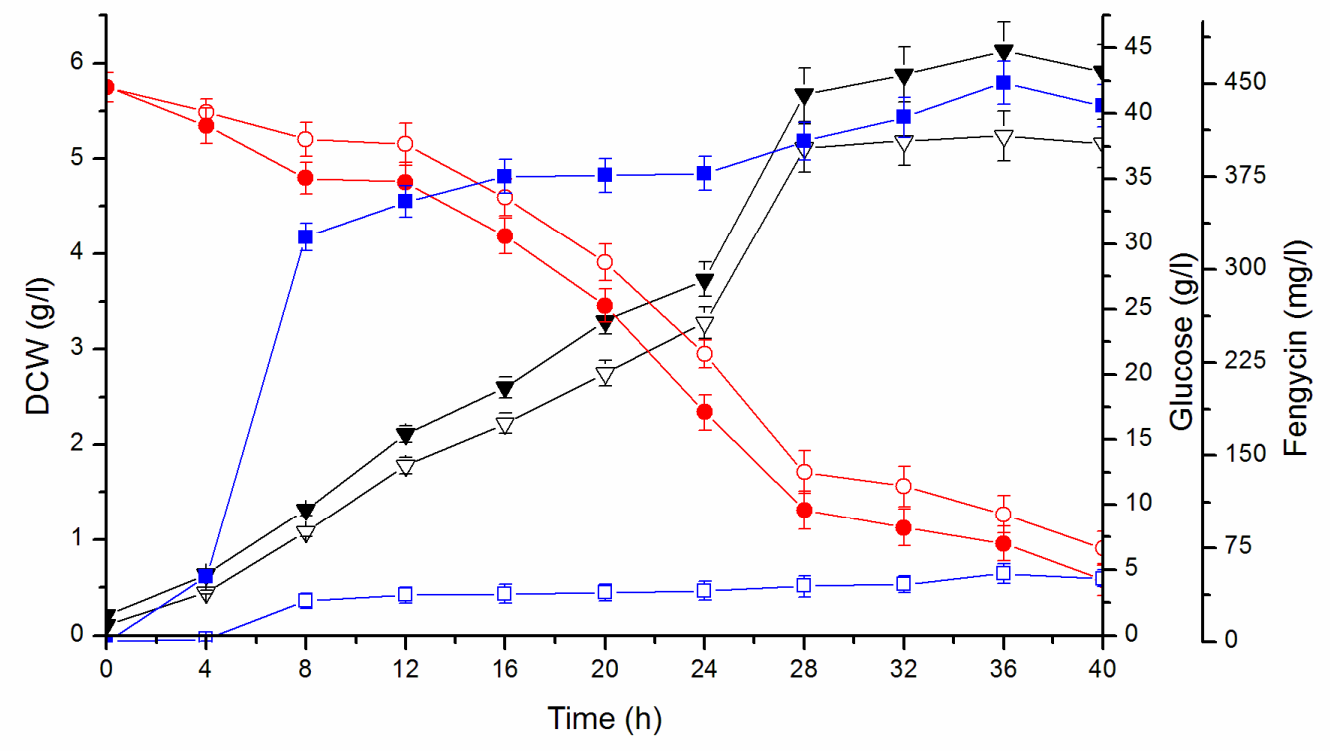

https://mc06.manuscriptcentral.com/cjm-pubs 
Figure 3

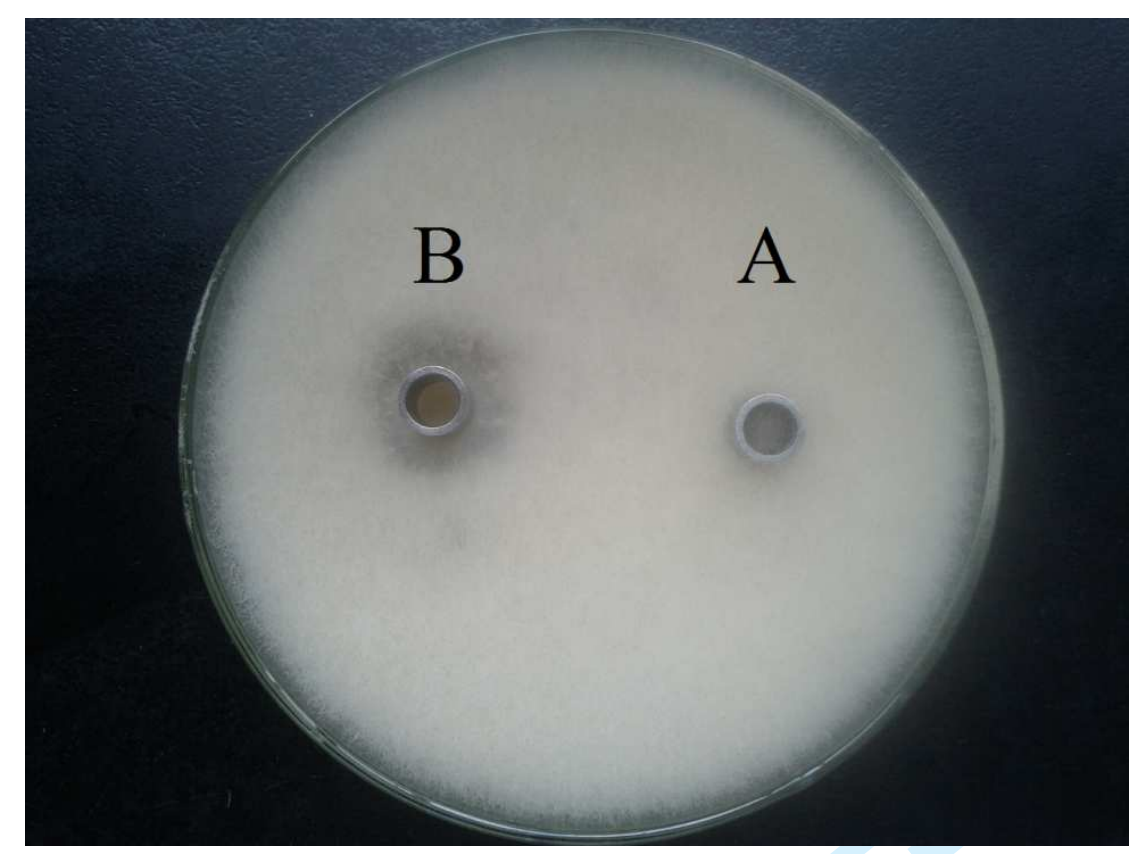

https://mc06.manuscriptcentral.com/cjm-pubs 
Figure 4

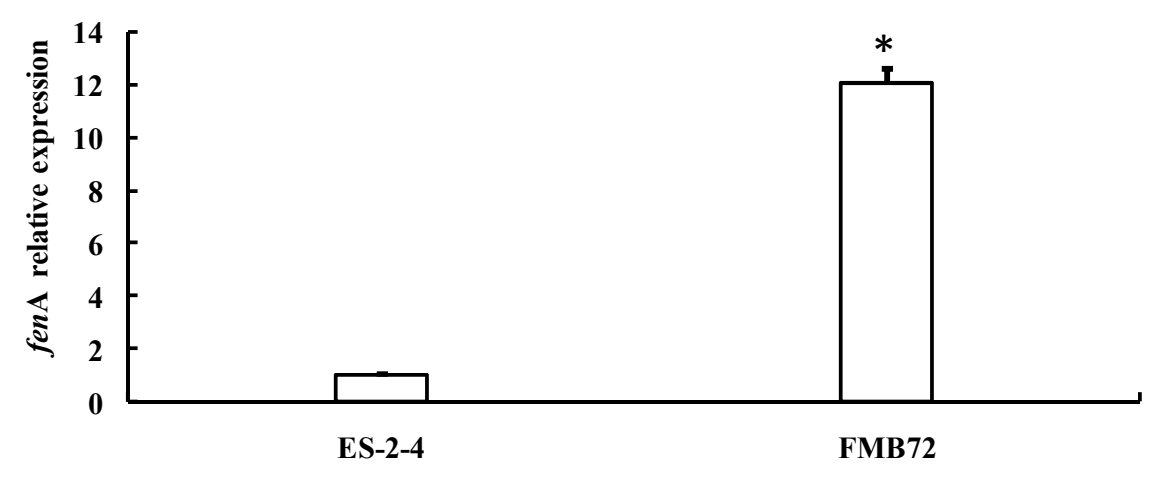

